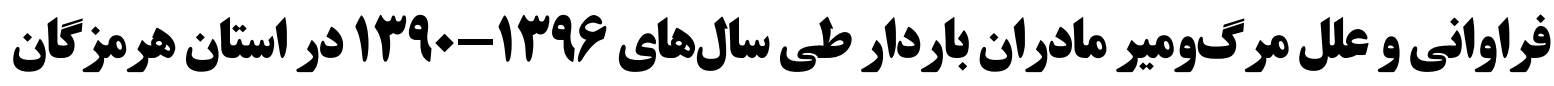

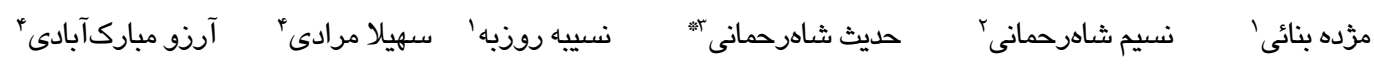

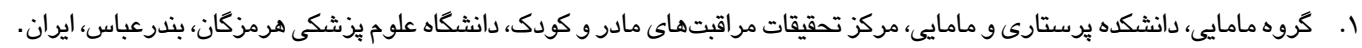

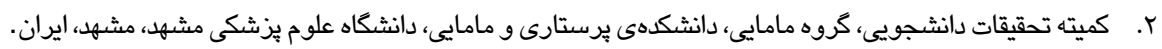

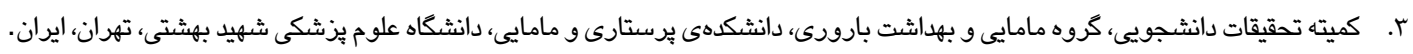

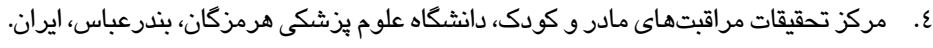

هدف: از آنجايى كه مرك مادر باردار سلامت خانواده و جامعه را تحت تأثير قرار مىدهد، شناخت علل و عوامل مـؤثر و ارائـهـ راهكارهـاى مناسب جهت كاهش مركومير ضرورى مى باشد. بنابراين مطالعه حاضر با هدف تعيين فراوانى و علل مركومير زنان باردار در استان هرمزكان انجام شد.

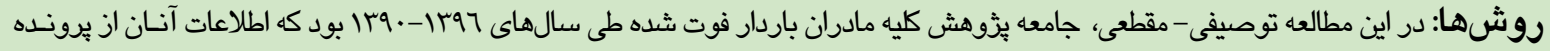

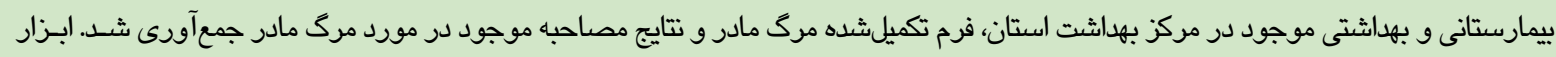

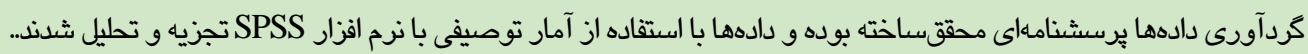

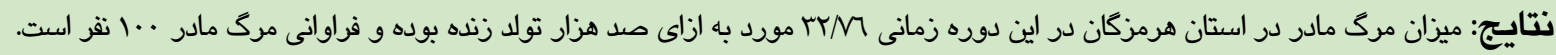

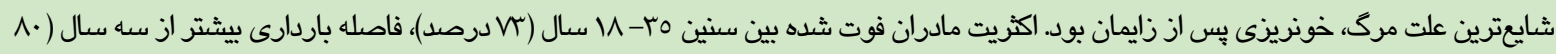

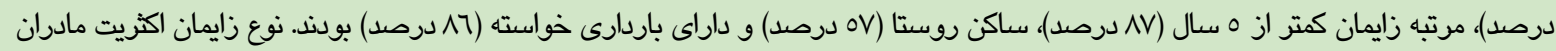

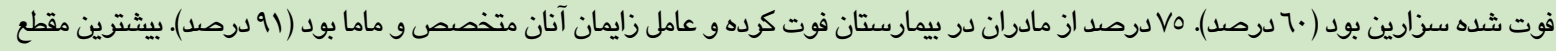

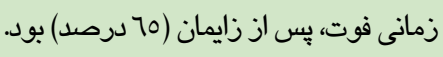

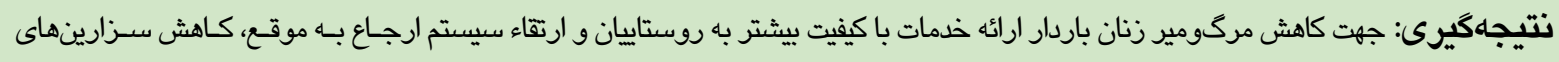

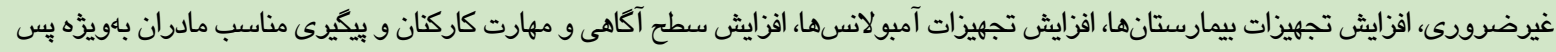

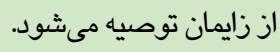
كليدوازمهـا: مرك مادرى، زنان باردار، حاملكى، زايمان، هرمزكان.

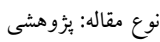

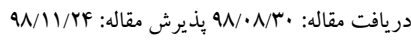

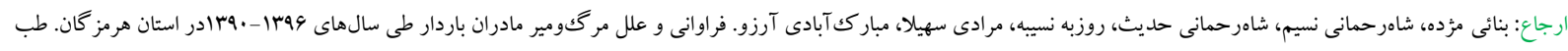

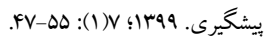

در حالى است كه عq درصد موارد مركَمير مادرى در

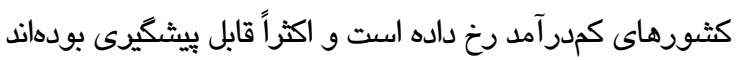
(Y) (Y). براساس كزارش سازمان جهانى بهداشت ميزان مرك مادر در سال IV IV در كثورهاى ايالاتمتحده امريكا مه مورد، ارويا rا مورد، افريقا Oro، آسياى جنوب شرقى بك 10، مديترانه شرقى ع7ا و در ايران 17 مورد به ازاي هر صد هزار تولد زنده كزارش شده است (ז). علاوه بر آن براساس آخرين بيانيه سازمان

\section{مقدمه}

مرك مادرى به مرك زن باردار در اثر باردارى و يا

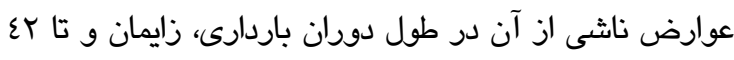

روز يس از زايمان اطلاق مىثود (1). در هر روز حدود •l1 زن باردار به علت عوارض قابل

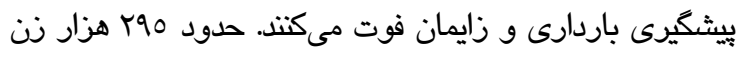
در سال IV أ در طول دوران باردارى و نفاس فوت كردند. اين 
جهت رسيدن به توسعه بِيدار بهاشت و سلامت همكانى، شناخت بيشتر عوامل مداخلكر در مرك مادران ضرورى است.

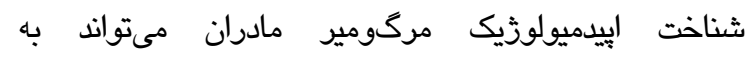
تصميمكيرىهاى استراتزيك براى كاهش هر جه بيشتر مركومير مادران كمك كند. از طرفى استان هرمزكان از نظر هرئر

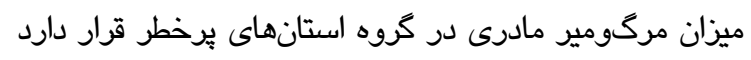

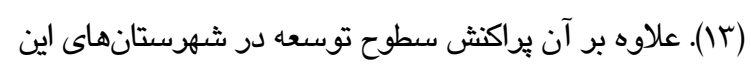
استان نامتعادل بوده و اين تقاوت در بخشهاى مختلف بهاشت درمان، آموزشى، فرهنكى، ارتباطى، رفاهى و زيربنايى ديده

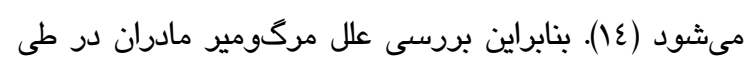
سالهاى مختلف و همجنين تعيين عوامل بيشكيرىكتنده و

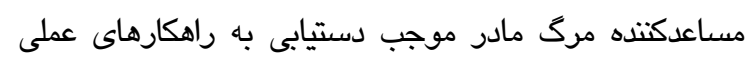

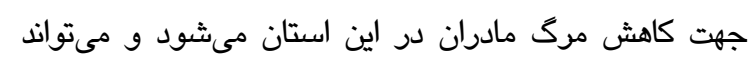

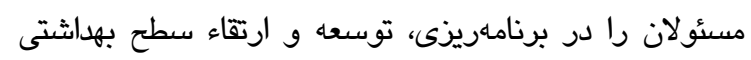

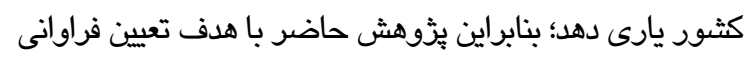

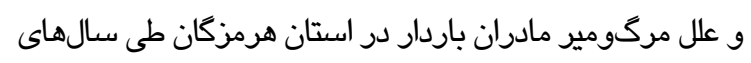

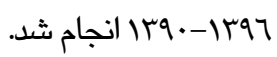

\section{مواد و روشها}

اين مطالعه از نوع توصيفى بود و به صورت مقطعى

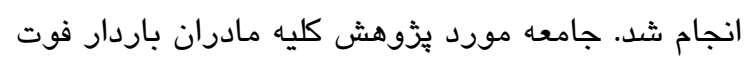

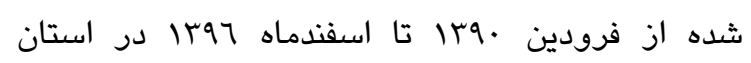
هرمزكان بود. - ان فرودين

براساس نظام كثورى مراقبت مادر، براى هر مادر

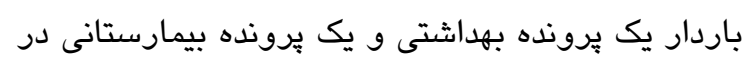

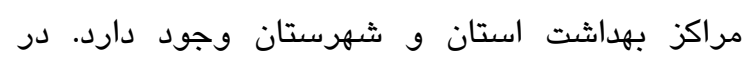
صورت وقوع هر مرك مادر ظرف مدت r هفته كميته

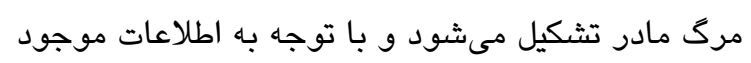
در برونده و نتايج بررسى كروه برسشكرى علت مرك هـ

$$
\text { مشخص و راهكارهاى آن ارائه مىشود. }
$$

جهانى بهداثت و اهداف توسعه بايدار اين شاخص مركومير

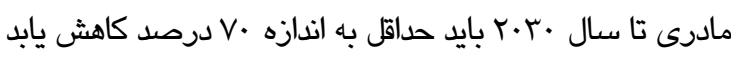

مادر هسته اصلى خانواده مىباشد و مرك مادر صدمات

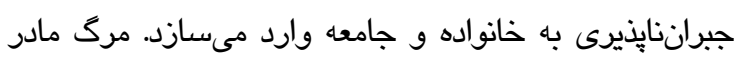
نثانكر حساسى از وضعيت اجتماعى و اقتصادى جامعه شامل وضعيت سواد زنان جامعه، ميزان دسترسى، كيفيت و كفايت مراقبتهاى بهداشتى، شبكههاى ارتباطى، ظرفيت سيستم ارائه

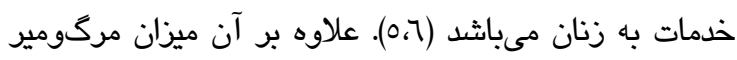
مادرى به عنوان شاخص مهمى از توسعه انسانى شناخته شده

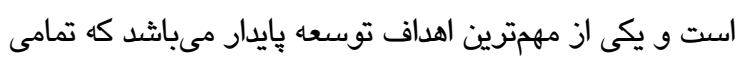
كثورها متعهة شدهاند كه در جهت كاهش مركومير مادران

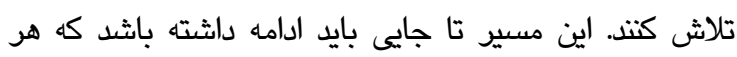
حاملكى خواسته و هر زايمان بدون عارضه باشد (V.N.). و همكاران در مطالعه خود شايعترين علل مركومير Say مادران در سطح جهان را به ترتيب خونريزى، اختلالات فثشارخون، سيسيس، سقط، آمبولى و ساير علل غيرمسنتيم كزارش كردهاند (9). همجنين در مطالعه زالوند و همكاران خونريزى (r./V درصد)، فشارخون (V/T درصد) و بيمارى قلبى- عروقى (I/N درصد) مهمترين علل مركومير مادر در

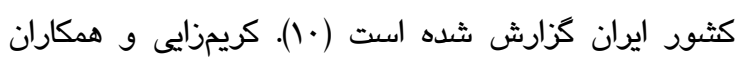

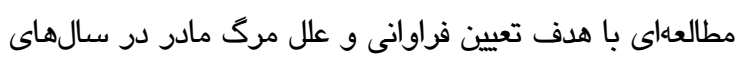

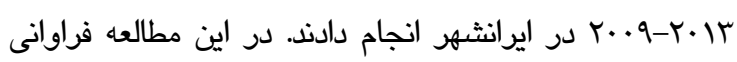
مرك مادر عَ بود. همجنين شايعترين علت مرك مادر به ترتيب خونريزى بِ از زايمان، بره اكلامسى و عفونت تثخيص داده ثد (II Arifeen. و همكاراندر مطالع خود بيان كردند ميزان

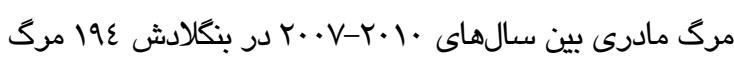

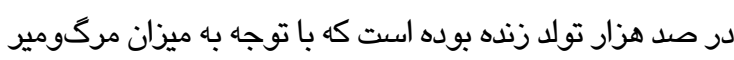
مادرى در سالهاى ا... - - 1991 ميانكين نرخ كاهش سالانه

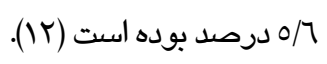


(صفر) بود. بيشترين نسبت مرگ مادر در سال .9r ا و كمترين نسبت در سال 97 ا بوده است (نمودار ().

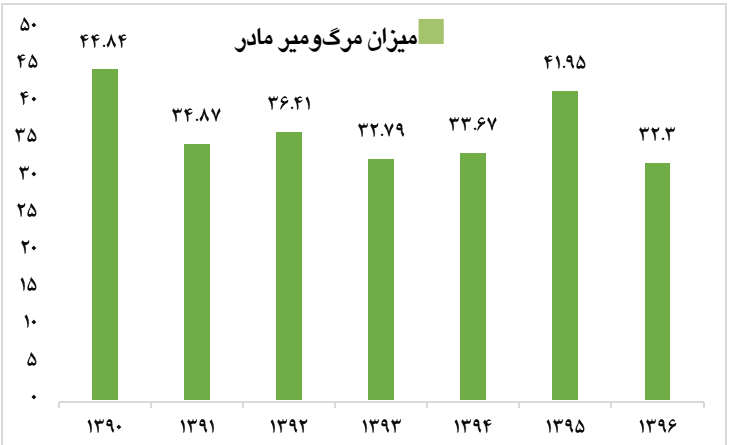

نمودار 1- روند تغييرات ميزان مرگومير زنان باردار در استان هرمزكان در يك دوره V ساله

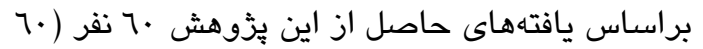
درصد) از مادران فوت شده از طريق سزارين زايمان كرده بودند. 7ع نفر (7ع درصد) از مادران فوت شده حداقل داراى يك عامل خطر و 17 نفر (17 درصد) از آنان داراى باردارى خواسته بودند. عامل زايمان 91 نفر (ا9 درصد) از مادران ماما و متخصص زنان بود. ساير متغيرهاى مرتبط با مركومير مادران در جدول بررسى شده است. همجنين نتايج اين مطالعه نثان داد كه شايعترين

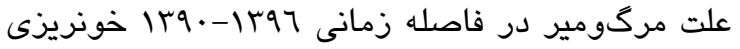

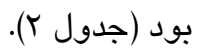

جدول ץ- توزيع فراوانى علل مركومير مادران در استان

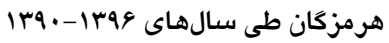

\begin{tabular}{|c|c|}
\hline فراوانى (درصد) & علت مرك مادر \\
\hline$(T \varepsilon) r \varepsilon$ & خونريزى \\
\hline (IV)IV & ساير \\
\hline (17)17 & اكلاميسى \\
\hline (IT)Ir & نامعلوم \\
\hline (II)川 & آمبولى \\
\hline (9) 9 & بيمارى زمينهاى \\
\hline (7) 7 & عفونت \\
\hline (0)0 & بيمارى قلبى \\
\hline$(1 \cdot \cdot)) \cdot$. & جمع كل \\
\hline
\end{tabular}

در اين يخذوهش اطلاعات مورد نظر از بِرونده بيمارستانى و بهداشتى موجود در مركز بهداشت استان، فرم تكميل شده مرك مادر و نتايج مصاحبه موجود در مورد مرك مادر جمعآورى شد. در صورت وجود هر كونه ابهام در يرونده يا اطلاعات ناقص، با مراجعه به بازماندكان متوفيان اطلاعات مورد نظر تكميل شد. ابزار كردآورى دادهها بِرسشنامهاى محققساخته و مشتمل بر سه قسمت بود. بخش اول شـامل اطلاعات دموكرافيك، بخش دوم شامل اطلاعات مامايى و زايمان و بخش سوم شامل اطلاعات تخصصى مربوط به مرى مادر است. روايیى يرسشنامه با روايى محتوى و يايايى ابراز با استفاده از روش آلفاكرونباخ و با ضريب همبستكى ^^ر, · مورد تاييد قرار كرفت. كليه دادهایى اخذ شده از يِرونده توسط سه يَّوهشكر كنترل شد. دادهها از طريق روشهاى آمار توصيفى (جداول و نمودار) مورد بررسى قرار كرفت. جهت رعايت ملاحظات اخلاقى تمامى اطلاعات به صورت كاملاً محرمانه و بلدون ذكر نام افراد و جمع آورى شد و براى انجام يَذوهش مجوزهاى لازم از معاونت يَّوهشى دانشكاه علوم يزشكى استان هرمزكان و مسئولين مربوطه شبكه بهداشت و درمان استان اخذ شد.

\section{يافتهها}

اين بِّوهش نشان داد كه در طول دوره V ساله تعداد

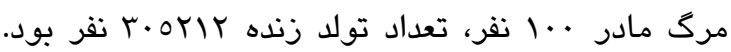
ثـاخص مركومير مادرى در استان هرمزكان در اين دوره زمانى T/VT بـ به ازاى هر .. هزار تولد زنده بود. بيشترين ميزان مرك مادر در شهرستان بندرعباس (r9) مورد) و كمترين ميزان آن در شهرستان ابوموسى 


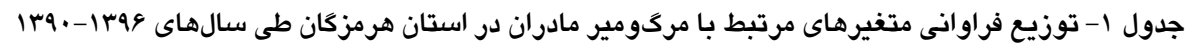

\begin{tabular}{|c|c|c|c|c|c|c|c|c|c|}
\hline جمع & Irq9 & 1790 & irqr & Irar & Irar & $|r q|$ & $1 r q$. & متغير & \\
\hline $\begin{array}{cc}r(r) \\
V r \quad(V r) \\
r_{0} \quad\left(r_{0}\right)\end{array}$ & $\begin{array}{cc}1 & (\Lambda / r) \\
q & \left(V_{0}\right) \\
r \quad(Y / T)\end{array}$ & $\begin{array}{c}(Y Y / Y) \\
1 Y \\
0(Y Y / Y)\end{array}$ & $\begin{array}{c}\text { (VA/OV) } \\
(Y) \\
(r) / \varepsilon r) \\
r\end{array}$ & $\begin{array}{c}(T q / r r) \\
q \\
(r \cdot / V T) \\
\varepsilon\end{array}$ & $\begin{array}{ll}v & (0 .) \\
v & (0 .)\end{array}$ & $\begin{array}{c}(9 r / r)) \\
\mid r \\
1(V / 79)\end{array}$ & $\begin{array}{c}r\left(Y / Y_{0}\right) \\
\text { Ir }\left(V_{0}\right) \\
\left(1 \wedge / V_{0}\right) \\
r\end{array}$ & 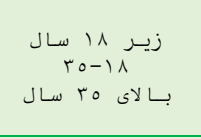 & سن \\
\hline $\begin{array}{ll}\varepsilon r & (\varepsilon r) \\
r q & (r q) \\
1 \wedge & (1 \wedge)\end{array}$ & $\begin{array}{ll}7 & (0 \cdot) \\
0 & (\varepsilon) / T) \\
1 & (1 / r)\end{array}$ & $\begin{array}{ll}V & (r \wedge / \wedge) \\
Y & (r r / r) \\
0 & (r V / V)\end{array}$ & $\begin{array}{c}(0 V /) \varepsilon) \\
\wedge \\
(r) / \varepsilon r) \\
r \\
(r) / \varepsilon r) \\
r\end{array}$ & $\begin{array}{c}(r \wedge / \Sigma T) \\
0 \\
(r \wedge / \Sigma T) \\
0 \\
(r r / \cdot V) \\
r\end{array}$ & $\begin{array}{c}\left(\sum Y / \wedge 0\right) \\
T \\
\left(\sum Y / \wedge 0\right) \\
T \\
(1 \leqslant / Y \wedge) \\
r\end{array}$ & $\begin{array}{c}(r \wedge / \varepsilon \tau) \\
0 \\
(T) / O r) \\
\wedge \\
.\end{array}$ & $\begin{array}{l}r(r V / 0) \\
7 \quad(r V / 0) \\
\varepsilon(r 0)\end{array}$ & 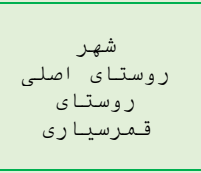 & سكونـت \\
\hline $\begin{array}{ll}r \cdot & (r \cdot) \\
\Lambda \cdot & (\Lambda \cdot)\end{array}$ & $\begin{array}{c}1(7 / / 7) \\
(9 r / \wedge \varepsilon) \\
11\end{array}$ & $\begin{array}{c}(7 / 17) \\
(9 r / \wedge \varepsilon) \\
\mid \vee\end{array}$ & $\begin{array}{c}(Y) / \varepsilon r) \\
r \\
(V \wedge / O V) \\
11\end{array}$ & $\begin{array}{c}(\varepsilon 7 / / 0) \\
7 \\
(0 r / \wedge \varepsilon) \\
V\end{array}$ & $\begin{array}{c}(r \circ / Y)) \\
0 \\
(r \leq / Y \Lambda) \\
q\end{array}$ & $\begin{array}{c}(r r / \cdot V) \\
r \\
(V V / q) \\
1 .\end{array}$ & $\begin{array}{c}1\left(T / Y_{0}\right) \\
(9 r / V T) \\
10\end{array}$ & $\begin{array}{l}<r \\
r \leq\end{array}$ & بـارد اصلـه \\
\hline $\begin{array}{l}\wedge V(\wedge V) \\
I r(\mid r)\end{array}$ & $\begin{array}{c}(91 / v) \\
11 \\
1(1 / r)\end{array}$ & $\begin{array}{c}(9 r / \wedge \varepsilon) \\
\mid \vee \\
1(7 / 17)\end{array}$ & $\begin{array}{c}(V \wedge / \circ V) \\
(Y) / \varepsilon r) \\
(r\end{array}$ & $\begin{array}{c}(\Lambda \varepsilon / 7)) \\
11 \\
(10 / r \wedge) \\
r\end{array}$ & $\begin{array}{c}(V) / \varepsilon r) \\
) \\
(r \wedge / 0 V) \\
\varepsilon\end{array}$ & $\begin{array}{c}(9 r / r)) \\
\mid r \\
1(V / 79)\end{array}$ & $\begin{array}{c}(9 r / V r) \\
10 \\
1\left(T / r_{0}\right)\end{array}$ & $\begin{array}{l}<0 \\
0 \leq\end{array}$ & 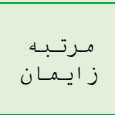 \\
\hline $\begin{array}{l}V_{0}\left(V_{0}\right) \\
\cdot \\
r(r) \\
I r(I T) \\
V(V)\end{array}$ & $\begin{array}{c}(\Lambda r / r) \\
1 \cdot \\
\cdot \\
1 \\
(\wedge / r) \\
1(1 / r) \\
\cdot\end{array}$ & $\begin{array}{c}(V V / V) \\
I \varepsilon \\
\cdot \\
\cdot \\
\varepsilon(Y Y / Y) \\
\cdot\end{array}$ & $\begin{array}{c}(V) / \varepsilon r) \\
1 \cdot \\
\cdot \\
(1) / r \wedge) \\
r \\
(1 \varepsilon / r \wedge) \\
r \\
r\end{array}$ & $\begin{array}{c}(V Y / q r) \\
1 \cdot \\
\cdot \\
(V / 7 q) \\
(10 / r \wedge) \\
r\end{array}$ & 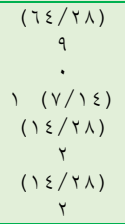 & $\begin{array}{c}(7 q / r r) \\
q \\
\cdot \\
\vdots \\
(r \cdot / V T) \\
\varepsilon \\
\cdot\end{array}$ & $\begin{array}{c}\left.(1) / r_{0}\right) \\
i r \\
\dot{r} \\
r(T / Y / 0) \\
1\left(T / Y_{0}\right)\end{array}$ & 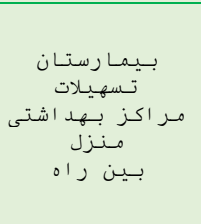 & مـحل فــوت \\
\hline $\begin{array}{ll}r_{0} & \left(Y_{0}\right) \\
1 \cdot & (1 \cdot) \\
r_{0} & \left(r_{0}\right)\end{array}$ & $\begin{array}{l}\varepsilon(r r / r) \\
r \quad\left(Y_{0}\right) \\
0 \quad(\varepsilon / V)\end{array}$ & $\begin{array}{c}\varepsilon(Y Y / Y) \\
r(I Y / T) \\
(T Y / T) \\
I Y\end{array}$ & $\begin{array}{c}(r \wedge / O V) \\
\varepsilon \\
(V / Y \varepsilon) \\
(7 \varepsilon / Y \wedge) \\
9\end{array}$ & $\begin{array}{c}(r \cdot / V T) \\
\varepsilon \\
\cdot \\
(7 q / r r) \\
q\end{array}$ & $\begin{array}{c}(I \varepsilon / r \wedge) \\
r \\
(V / T \varepsilon) \\
(V \wedge / O V) \\
11\end{array}$ & $\begin{array}{c}(r \cdot / V T) \\
\varepsilon \\
(r r / \cdot V) \\
r \\
(\varepsilon T / 10) \\
T\end{array}$ & $\begin{array}{c}\left(1 \wedge / V_{0}\right) \\
r \\
\left.(\Lambda) / r_{0}\right) \\
1 r\end{array}$ & 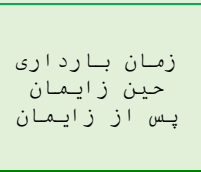 & زمــــــــ \\
\hline
\end{tabular}

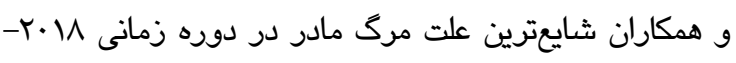

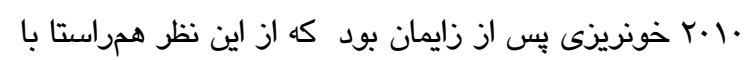
مطالعه حاضر مىباثد (M) اما در كثور آرزانتين شايعترين علت مرك مادران اختلالات فثارخون در باردارى كزارش شد (19). خونريزى بِ از زايمان يكى از سه علل اصلى مركومير مادران و يك عامل تهديدكتنه حيات در سرتاسر جهان است (r.). خونريزى شديد بِ از زايمان مىتواند در عرض جند ساعت باعث مرك مادر شود (()؛ بنابراين دسترسى سريع به فرآوردههاى خونى، اقدامات اورزانس مامايى و ارجاع سريع به مراكز تخصصى مجهز مىتواند در نجات جان مادر مؤثر باشد. براساس تتايج به دست آمده از مطالعه حاضر بيثترين

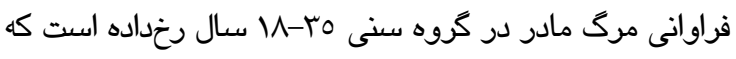
با مطالعه جمشيديور و همكاران و شهيدى و همكاران همراستا مىباثد اما با مطالعه MacDorman و همكاران همراستا نبود

\section{بحث و نتيجه كيرى}

هدف از اين مطالعه تعيين فراوانى و علل مركومير مادران باردار استان هرمزكان در بازه زمانى هفتساله بين سالهاى .

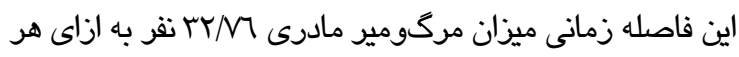
صد هزار تولد زنده بوده است. روند كلى مركومير در اين

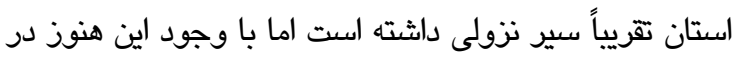
سطح بالايى مىباشد و از برخى از كشورهاى خاورميانه ماتت

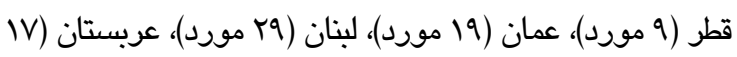
مورد)، كويت (T ا مورد) و مصر (TV مورد) بيشتر مىباثد (T). يافتهاى مطالعه حاضر نشان مىدهد شايعترين علت مرك خونريزى بِ از زايمان مىباثد. در استانهاى سيستان و بلوجستان (10)، اصفهان (17) و سمنان (IV) نيز شايعترين علت El-Kak رك مادران خونريزى كزارش شده است. در مطالعه 
در يك مطالعه حدود 1/0 ميليون باردارى مورد بررسى قرار كُفت و نتايج نشان داد زايمان سزارين خطر مركَ مادر را Iا برابر افزايش مىدهد (9). بنابراين سزارين يكى از مهرترين عوامل خطر مركومير زنان باردار محسوب مىشود و اقدامات اساسى جهت كاهش ميزان سزارين تأثير به سزايى در كاهش مركَومير مادرى دارد. بيشتر مادران فوت شده در اين بِّوهش فاصله باردارى بيشتر از r سـال و تعداد باردارى كمتر از 0 عدد داثتند. در مطالعه Ntoimo و همكاران اه درصد مركها در

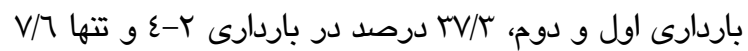
درصد از مرك مادران در باردارى بالاى ه رخداده بود (Y^). رجايى و همكاران نيز در يُخوهش خود كَارش كردند باردارى اول و دوم نسبت به باردارىهاى متعددتر، عامل خطر عمدهترى براى مركومير مادر محسوب مىشود كه دليل آن ممكن است عدم تجربه و آكاهى مادران و ناثناخته بودن بيمارىهاى زمينهاى باشد (·r). بنابراين افزايش آكاهى خانوادهها در مورد باردارى، و افزايش يوشش مراقبتها توصيه مىكردد. در مطالعه محمدىنيا و شهيدى و همكاران تعداد بالاى باردارى به عنوان عامل خطر مركومير مادرى عنوان شد كه از اين نظر با نتايج مطالعه ما مغايرت دارد (Y. (10،). در يثوهش حاضر بيشترين موارد مركومير مادران مربوط به دوران يس از زايمان بود كه با مطالعه زارعان و همكاران و محمدى نيا و همكاران همراستا بود (10.17). عدم انجام مراقبتهاى لازم، كامل، صحيح و به موقع توسط كادر درمانى، بىتوجهى و علم حساسيت مادر و خانواده و همجنين عدم دريافت مراقبت پِ از زايمان از مهرترين دلايل فوت مادر ״يس از زايمان مىباثد. براساس اين نتايج مراقبتهاى يّ از زايمان داراى اهميت ويزهاى مىباشند. بنابراين تلاش براى افزايش بيوشش و بهبود كيفيت خدمات و افزايش آكاهى مادر و خانواده، بيكيرى مادران در اين دوره، همجنين شناسايع عوامل مرتبط با عدم انجام اين مراقبتها مىتواند سهم بسزايى در كاهش مركومير مادران داثته باثد.

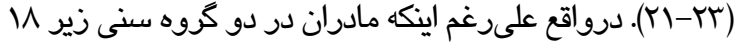
سال و بالاى مr سال از نظر عوارض باردارى و زايمان در معرض خطر بيشترى قرار دارند اما در اين كروه سنى به علت تعداد بالاى باردارى، ميزان مرك مير بيشترى كَارش مىشود. بنابراين اهميت بيشتر در زمينه تتظيم خانواده و توجه هر جه بيشتر مادران در اين سنين توصيه مىشود. در مطالعه حاضر اكثر مركَ مادران در بيمارستان رخ داده بود و زايمان توسط متخصص زنان يا ماما انجام شده بود. در مطالعه كريمىزارجى و همكاران و درصد از مرك مادران در ييمارستان رخداده بود (عץ). Mgawadere و همكاران در مطالعه خود مركَ عq مادر باردار در بيمارستان و مراكز درمانى را مورد ارزيابى قرار دادند. نتايج مطالعه آنها نشان داد كه مهمترين علت مرگ مادر در بيمارستان به ترتيب شامل مدت طولانى انتظار قبل از معالجه در يك مركز درمانى، كمبود تجهيزات و امكانات، تثخيص اشتباه، درمان نادرست، سيستم ارجاع ناكافى، عدم صلاحيت، دسترسى و مهارت كاركنان و كمبود كادر باصلاحيت بود (Yo). در واقع مهمترين عامل زمينهساز مرك مادر عوامل نيروى انسانى ارائهكتده خدمت ثنامل تأخير در تشخيص، درمان، بيكيرى بيمار، استفاده از درمان غير مؤثر، كوتاهى در ارجاع به موقع و نقص در ارائه خدمات درمانى از طرف ردههاى مختلف تخصصى و غيرتخصصى مىباش د(YT). بنابراين مجهز كردن بيمارستانها، ارائه خدمات باكيفيت در اورزانسهاى مامايى و دسترسى آنان به مايعات و بانك خون توصيه مىكردد. در اين يُّوهش اكثر موارد مركَومير به روش سزارين زايمان كرده بودند. از اين نظر يافتهايى مطالعه ما با بزّوهش مرادان و همكاران و شهيدى و همكاران مشابه بود ، اما با مطالعه سارانى و همكاران و Ntoimo و همكاران مغايرت داثت (IV.TY.TV،YA) مركَومير به علت زايمان سزارين تأييدشده است ( آ). 
كاركنان و افزايش حساسيت آنان در شناسايى باردارىهاى برخطر، افزايش بوشش خدمات تتظيم خانواده افزايش آكاهى خانوادها در مورد باردارى، افزايش بِوشش مراقبتها در سراسر دورهى باردارى و به ويزه بِ از زايمان، شناسايى به موقع و ارجاع سريع و بيكيرى مادران برخطر، توجه به افزايش تجهيزات بيمارستانها و آمبو لانسها توصيه مىشيعود.

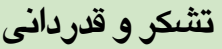

بلدينوسيله از معاونت بِّوهشى دانشكاه علوم يزنشى هرمزكان، مسئولان مربوطه شبكه بهداشت و درمان استان، اداره سلامت مادران استان و خانواده متوفيان شركتكتند در اين بذوهش تقدير و تثكر مىكنيم.

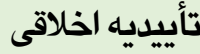

اين مقاله بركرفته از طرح تحقيقاتى مصـوب جلسـهـ

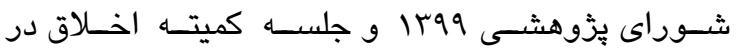

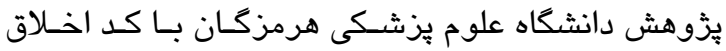
IR.HUMS.REC.1399.051

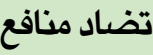

نويسندكان هيجكونه تضاد منافعى ندارند.

\section{سهم نويسندكان}

مزده بنايى (نويسنده اول) نكارش مقاله (·r درصد)، نسيم شاهرحمانى (نويسنده دوم) روش شناسى (•إدرصد)، حديث

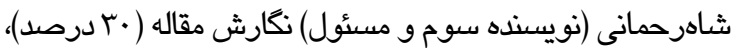

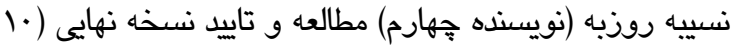

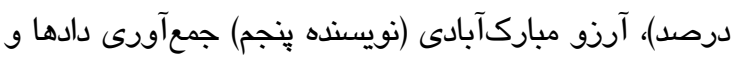
سهيلا مرادى (نويسنده ششم) جمع آورى دادهها (.r درصدا.

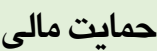

تتايج نثان داد كه بيشترين افراد فوت شده، ساكن روستا بودند. در مطالعه مجمدى نياو همكاران نيز سكونت در روستا

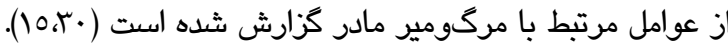
در كثورهاى در حال توسعه نيز عدم دسترسى به مراقبتها و سكونت در روستا از عوامل خطر محسوب مىشود (TV). در واقع دورى مسافت، عدم دسترسى به مراقبتهاى فورى مامايى به علت ضعف سيستمهاى ارجاع از مهمترين علتهاى مركومير مادران در روستا محسوب مىشود. بنابراين ارتقا دسترسى به خدمات و همجنين ايجاد سيستمهاى ارتباطى مناسب و سريع در برخورد با عوارض مامايى مىتواند به عنوان يكى از راهكارهاى مهم در كاهش مركومير مادرى موردتوجه قرار كيرد. در مطالعه Peisino و همكاران بيشترين افراد فوت شده ساكن شهر بودند (19). شايد بتوان بيان كرد يكى از دلايل وجود اين تفاوت تعداد، جمعيت بيشتر ساكن در شهر مىباشد. در اين بذوهش بيشترين ميزان مرك مادر در شهرستان بندرعباس رخداده بود. بالاتر بودن مرك مادر در اين شهرستان مىتواند به علت جمعيت بيشتر، بالاتر بودن ميزان بارورى كلى و وجود مناطق حاثيهنثين فقير در اطراف اين شهرستان باثد. كمترين ميزان مركومير در شهرستان ابوموسى بود. اين شهرستان با توجه به شرايط خاصى كه دارد يكى از

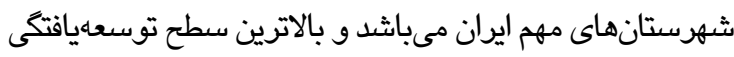
در استان هرمزكان مربوط به شهرستان ابوموسى مىباشد. از محدوديتهاى مطالعه حاضر مىتقان به كنشتهنكر بودن مطالعه و عدم وجود كروه كتترل جهت ارزيابى علل مرك مادران اشاره كرد. از نقاط قوت مطالعه بررسى و كتترل دادهها توسط

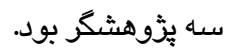
از تتايج اين مطالعه مىتوان براى شناسابي بيشتر عوامل مؤثر در مرك مادر با انجام يزوهشهاى بيشتر و در تتيجه انجام برنامهريزى، توسعه و ارتقاء سطح بهاشتى جهت كاهش مركومير استان استفاده كرد. مطالعه و عوامل خطر شناخته شده مرك مير در اين استان، آموزش و افزايش آكاهى و مهارت 


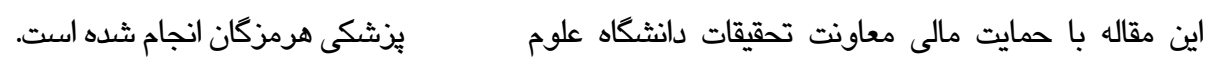

\section{References}

1. Cunningham F, Leveno K, Bloom S, Spong CY, Dashe J. Williams obstetrics. 25th ed. New York: McGraw Hill; 2018.

2. World Heakth Organization. Maternal mortality. Available from: https://www.who.int/news-room/factsheets/detail/maternal-mortality

3. World Health Organization, UNICEF, United Nations Population Fund, World Bank Group, The United Nations Population Division. Trends in maternal mortality 2000 to 2017 . Geneva: World Health Organization; 2019.

4. United Nations Statistical Commission. Global indicator framework for the Sustainable Development Goals and targets of the 2030 Agenda for Sustainable Development. San Francisco: United Nations; 2017

5. Mobasheri M, Khalafian $\mathrm{P}$, Alidosti M, Salehifard AZ. Study of pregnant women's mortality in Chaharmahal va Bakhtiari province in a 10-year period (2002-2012). J Clin Nurs Midwifery. 2014; 3(2):21-9. [Persian]

6. Abdolahpour P, Babaei M, Gasemi YM. Causes of maternal mortality in pregnant women in urban and rural areas of Ilam, Iran. J HSR. 2011; 7(6):1278-87. [Persian]

7. Asefzadeh S, Alijanzadeh $\mathrm{M}$, asl $\mathrm{MN}$. Correlation between human development index and maternal mortality rate. Payesh. 2013;12(6):559-66 .[Persian]

8. Callister LC, Edwards JE. Sustainable development goals and the ongoing process of reducing maternal mortality. J Obstet Gynecol Neonatal Nurs. 2017; 46(3): e56-e64. Doi: 10.1016/j.jogn.2016.10.009

9. Say L, Chou D, Gemmill A, Tunçalp Ö, Moller A-B, Daniels J, et al. Global causes of maternal death: A WHO systematic analysis. Lancet Glob Health. 2014; 2(6):e323-e33. DOI: $10.1016 / \mathrm{S} 2214-109 \mathrm{X}(14) 70227-\mathrm{X}$
10. Zalvand R, Tajvar M, Pourreza A, Asheghi H. Determinants and causes of maternal mortality in Iran based on ICD-MM: A systematic review. Reprod Health. 2019; 16(1):16. DOI: 10.1186/s12978-019-0676-y

11. Karimzaei T, Zareban I, Jamalzae A-Q, Darban F, Bakhshani KD, Balouchi A. Fequency of maternal mortality in urban and rural areas of Iranshahr county (Southeast of Iran) in 2009-2013: A retrospective study. J Clin Diagn Res. 2016; 10(8):QC14-17. Doi: 10.7860/JCDR/2016/19700.8372

12. El Arifeen S, Hill K, Ahsan KZ, Jamil K, Nahar Q, Streatfield PK. Maternal mortality in Bangladesh: a Countdown to 2015 country case study. The Lancet. 2014; 384(9951):1366-74. Doi: 10.1016/S01406736(14)60955-7

13. Kamiabi F, Torkestani T, Abedini M, HajiMaghsoudi S, Rastegari A, Hejazi S, et al. Analysis of the Maternal Mortality in Iran, 2007-2012. JKMU. 2015; 22(6):650-68.

14. Taghvaei M, Saboori M. Determining and analysis the development levels and degree of townships in Hormozgan province. Geography and Environmental Planning. 2012; 23(2):53-68. [Persian]

15. Mohammadinia N, Samiezadeh Toosi T, Rezaei MA, Rostaei F. Investigating the frequency and effective factors on maternal mortality in Sistan and Baluchistan province, Iran, 2002-2009. IJOGI. 2013; 16(44):28-34. [Persian] Doi: 10.22038/ijogi.2013.653

16. Zarean E, Bina R. Investigate the causes of maternal morbidity during 2006-2011 in Isfahan. HSR. 2014; Special Issue on Health Education: 2056-63. [Persian].

17. Moradan S, Forouzesh Far M. Prevalence and causes of maternal mortality in a 10-year period in a university hospital in Semnan. IJOGI. 2012; 15(3):1-7. [Persian] Doi: 10.22038/ijogi.2012.5733 
18. El-Kak F, Kabakian-Khasholian T, Ammar W, Nassar A. A review of maternal mortality trends in Lebanon, 2010-2018 Int J Gynaecol Obstet. 2020; 148(1):14-20. Doi: 10.1002/ijgo.12994

19. Peisino ME, de León RGP, Demaría MJ, Díaz A, Acevedo G. Maternal mortality in Cordoba city, Argentina: Causes, determinants and trends. Science. 2020; 8(1):1-7. Doi: 10.11648/j.sjph.20200801.1

20. Cunningham F, Leveno K, Bloom S, Spong CY, Dashe J. Williams obstetrics. 24th ed. New York: McGraw Hill; 2014.

21. Jamshidpour M, Izadi N, Najafi F, Khamoshi F, Roustaei Shirdel A, Jalili K. Determining the frequency and causes of maternal mortality in Kermanshah province. IJOGI. 2015; 18(136):15-21. [Persian] Doi: 10.22038/ijogi.2015.5334

22. Shahidi M, Komeili Z, Naemi H, Baghani R, Hosseinzadeh A. Prevalence and risk factors of maternal mortality in a 10-year period (2003-2013) in Sabzevar. Journal of Sabzevar university of medical sciences. 2017; 23(6):882-7. [Persian] Doi: 10.21859/sums2306882

23. Mac Dorman MF, Declercq E, Thoma ME. Trends in Texas maternal mortality by maternal age, race/ethnicity, and cause of death, 2006-2015. Birth. 2018; 45(2):169-77. Doi: 10.1111/birt.12330

24. Karimi-Zarchi M, Ghane-Ezabadi M, Vafaienasab M, Dehghan A, Ghasemi F, Zaidabadi M, et al .Maternal mortality in Yazd province, Iran. Electron Physician. 2016; 8(2):1949-54. Doi: 10.19082/1949

25. Mgawadere F, Unkels R, Kazembe A, van den Broek N. Factors associated with maternal mortality in Malawi: Application of the three delays model. BMC Pregnancy Childbirth. 2017; 17(1):219. Doi: 10.1186/s12884-017$1406-5$

26. Farrokh Eslamo HR, Nannbakhsh F, Heshmati F, Afsaneh AA. Epidemiology of maternal death in the Azarbayjan. Stud Med Sci. 2006; 17(1):31-23. [Persian]

27. Sarani M, Shahraki Z, Shirazi M, Saravani S. Risk factors of maternal mortality in Sistan region: 10-year report. Tehran Univ Med J. 2014; 72(9):623-9. [Persian]

28. Ntoimo LF, Okonofua FE, Ogu RN, Galadanci HS, Gana M, Okike ON, et al. Prevalence and risk factors for maternal mortality in referral hospitals in Nigeria: a multicenter study. Int J Womens Health. 2018; 10:69-76. Doi: 10.2147/IJWH.S151784

29. Clark SL, Belfort MA, Dildy GA, Herbst MA, Meyers JA, Hankins GD. Maternal death in the 21st century: causes, prevention, and relationship to cesarean delivery. Am J Obstet Gynecol. 2008; 199(1):36. e1-. e5. Doi: 10.1016/j.ajog.2008.03.007

30. Rajaee M, Zare S, Dadipour S, Fallahi S, Rajaee F, Pourahmad F, et al. Determining the frequency and causes of maternal mortality in Hormozgan province, Iran during 2005-2011. IJOGI. 2014;16(87):9-14. [Persian] Doi: 10.22038/ijogi.2014.2432 


\title{
Prevalence and causes of maternal mortality during the years 2011-2017 in Hormozgan province
}

\author{
Mojdeh Banaei ${ }^{1}$ \\ Nasim Shahrahmani ${ }^{2}$ \\ Hadis Shahrahmani ${ }^{3}$ \\ Nasibeh Rouzbeh ${ }^{1}$ \\ SoheilaMoradi $^{4}$ \\ Arezo Mobarak Abadi ${ }^{4}$
}

1. Department of Midwifery, Faculty of Nursing and Midwifery, Mother and Child Welfare Research Center, Hormozgan University of Medical Sciences, Bandar Abbas, Iran.

2. Student Research Committee, Department of Midwifery and Reproductive Health Research Center, Faculty of Nursing and Midwifery, Mashhad, University of Medical Sciences, Mashhad, Iran.

3. Student Research Committee, Department of Reproductive Health Midwifery, Faculty of Nursing and Midwifery, Shahid Beheshti University of Medical Sciences, Tehran, Iran

4. Mother and Child Welfare Research Center, Hormozgan University of Medical Sciences, Bandar Abbas, Iran.

\begin{abstract}
Introduction: Since the mathernal death affects the family and society's health, recognizing the causes and finding the preventive measures is essential. The aim of this study was to determine the prevalence and causes of mortality in pregnant women in Hormozgan province.

Methods: In this descriptive cross-sectional study, the study population was all pregnant mothers who died during the years 1390-1391. The information was collected from the hospitals, records available at the provincial health center, the completed maternal death forms, and the interviews on maternal death. Data collection tool was a researcher-made questionnaire and the data were analyzed using descriptive statistics with SPSS software.

Results: The rate of maternal death in Hormozgan province in the study period was 32.76 cases per 100,000 live births and the frequency of maternal death was 100 . The most common cause of death was postpartum hemorrhage. The majority of deceased mothers were 18-35 years old (73\%), with pregnancy interval more than three years (80\%), delivery times less than 5 (87\%), rural resident (57\%), and wanted pregnancy (86\%). The type of delivery was cesarean section in the majority of mothers who died (60\%). In addition, $75 \%$ of the mothers were died in hospitals and specialists and midwives were helping them to deliver (91\%). The highest mortality rate was related to post-delivery period $(65 \%)$.

Conclusion: In order to reduce the mathernal mortality, it is recommended to provide high quality services to the villagers and promote the referral system, quality of services to villagers, midwifery protocols, ambulance and hospital equipments, the level of knowledge and skills of staff, and follow up system and to reduce the unnecessary cesarean sections.
\end{abstract}

Key words: Maternal Death, Pregnant Women, Pregnancy, Parturition, Hormozgan.

Original Article

Received: 21 NovFeb $2019 \quad$ Accepted: 13Feb 2020

Citation: Banaei M, Shahrahmani N, Shahrahmani H, Rouzbeh N, Moradi Abadi S. Prevalence and Causes of Maternal Mortality during the years 2011-2017 in Hormozgan province. JPM. 2020; 7(1):47-55.

Correspondence: Hadis Shahrahmani. Student Research Committee, Department of Reproductive Health Midwifery, Faculty of Nursing and Midwifery, Shahid Beheshti University of Medical Sciences, Tehran, Iran Tel: +989139962372 ～Email: hadis.shahrahmani@gmail.com ORCID: 0000-0002-6066-3792 